O R I G I N A L

$\begin{array}{lllllllllllll}A & R & T & \text { I } & \text { C } & \text { L } & \text { E }\end{array}$

\title{
Fetal fibronectin test on Chinese women with symptoms of preterm labour: a pilot study
}

Objective The fetal fibronectin test is advocated to facilitate the management of women presenting with threatened preterm labour, but is underutilised in Hong Kong. This study aimed to provide experience with this test and evaluate its utility in a local setting.

Design Prospective cohort study.

Setting A university-affiliated hospital in Hong Kong.

Patients Women presenting with symptoms of preterm labour were recruited from 1 January 2011 to 30 June 2012.

Main outcome measures The sensitivity, specificity, positive predictive value, and negative predictive value of the fetal fibronectin test to predict delivery within 24 hours, 48 hours, 7 days, and 14 days.

Results A total of 22 women were recruited; 12 (55\%) of whom had a negative fetal fibronectin test, none of whom delivered within 7 days; six received corticosteroids and tocolysis, one of whom delivered within 14 days. The 10 remaining women had a positive fetal fibronectin test. Five of whom delivered within 7 days and two within 14 days; all of them had received corticosteroids and tocolysis. For predicting delivery within 7 days, the sensitivity and negative predictive value of the test were both $100 \%$.

Conclusions Our study demonstrated the high negative predictive value of the fetal fibronectin test in our local setting, which suggests that it should be utilised more readily in women presenting with threatened preterm labour.

Key words

Cervical length measurement Fibronectins; Obstetric labor, premature; Predictive value of tests

Hong Kong Med J 2013;19:424-8 DOI: $10.12809 / \mathrm{hkmj} 133861$

Department of Obstetrics and Gynaecology, Queen Mary Hospital, The University of Hong Kong, Pokfulam,

Hong Kong

KW Cheung, MB, BS, MRCOG SF Ngu, MB, BS, MRCOG CP Lee, MB, BS, FRCOG

Correspondence to: Dr KW Cheung Email: kelvincheung82@hotmail.com

\section{Introduction}

Preterm birth is a major challenge to perinatal health. It accounts for $75 \%$ of perinatal deaths and more than $50 \%$ of long-term neurological disabilities. ${ }^{1,2}$ The frequency of preterm births is increasing worldwide, due to the use of assisted reproductive techniques coupled with the increasing frequency of multiple pregnancies. ${ }^{1,2}$

The traditional approach to predicting preterm labour was to identify risk factors, detect persistent uterine contractions, and look for progressive cervical dilatation and effacement. However, most women do not have risk factors. Moreover, only about $10 \%$ of spontaneous early preterm births are associated with a history of prior preterm labour, and the symptoms and signs that ensue are often vague and non-specific. ${ }^{3,4}$ Because of the poor sensitivity and positive predictive value (PPV) of symptoms and signs of preterm labour, early detection has been difficult. Hence, both overdiagnosis and early initiation of tocolysis and corticosteroids are common. Recent studies have shown that repeated courses of corticosteroids are associated with decreased weight, length, and head circumference of the fetus at birth, ${ }^{5}$ and tocolysis also has adverse effects. Therefore, tocolytics and corticosteroids should be used with caution. ${ }^{6}$ 
The prediction of preterm birth is challenging. In recent years, the fetal fibronectin (FFN) test has been used to predict preterm labour. Fetal fibronectin is a glycoprotein found in the extracellular substance of the decidua basalis next to the placental intervillous space. ${ }^{7}$ It is localised between the chorion and decidua. The obliteration of the extra-amniotic space, and close approximation of the chorion and decidual surface results in disappearance of FFN in vaginal secretions from 20 weeks of gestation onwards. Detection of FFN in vaginal secretions thereafter may therefore represent pathological disruption of the maternal fetal interface and help to indicate genuine preterm birth. Due to its high negative predictive value (NPV), a negative test therefore helps to predict symptomatic women who will not deliver within 7 days.-9

The use of the FFN test for the management of women with symptoms of preterm labour is recommended by the American College of Obstetricians and Gynecologists ${ }^{10}$ and the Royal Australian and New Zealand College of Obstetricians and Gynaecologists. ${ }^{11}$ However, the test is underutilised in Hong Kong and local data are lacking. We therefore conducted a pilot study to provide experience and evaluate the accuracy of the test in a local setting. Our objective was to determine the sensitivity, specificity, PPV, and NPV of the FFN test as a predictor of delivery within 24 hours, 48 hours, 7 days, and 14 days.

\section{Methods}

This was a prospective observational study conducted between 1 January 2011 and 30 June 2012 in the Department of Obstetrics and Gynaecology of Queen Mary Hospital, Hong Kong. Chinese women with gestational ages of $24^{+0}$ to $33^{+6}$ weeks, who presented with symptoms or signs of threatened preterm labour, were studied. Threatened preterm labour was defined as uterine contractions detected by the tocodynamometry with symptoms of abdominal pain or vaginal bleeding before term. Women were given an information sheet about the study and the use of the FFN test. Inclusion criteria were age of $\geq 18$ years, with more than six contractions per hour by external tocodynamometry and cervical dilatation of $\leq 3 \mathrm{~cm}$. Women were excluded if they had premature rupture of membranes, triplet or greater number of pregnancies, a prior fetal FFN test performed elsewhere, prior cervical examination or sexual intercourse within 24 hours, a history of prior tocolysis, moderate or heavy vaginal bleeding, cervical cerclage, placenta praevia, or known congenital anomaly of their fetus. All women gave written informed consent and were enrolled under protocols approved by the Institutional Review Board of The University of Hong Kong/Hospital Authority Hong Kong West Cluster.

\section{替有早產症狀的華籍產婦進行胎兒繊連蛋白測試 的先導研究}

目的 胎兒繶連蛋白測試可用於預測早產風險, 從而加強對 產婦的護理，可惜這測試在香港並未得到充分利用。 本研究旨在分享使用胎兒纖連蛋白測試的經驗, 以及 評估胎兒纖連蛋白測試在本地運用的準確性。

設計 前瞻性隊列研究。

安排 香港一所大學的附屬醫院。

患者 2011 年1月1日至2012年6月30日期間出現早產症狀的 婦女。

主要結果測量 胎兒織連蛋白測試於 24 小時、48小時、7 天及 14 天預 測分娩的敏感性、特異性、陽性預測值和陰性預測 值。

結果 22 名參與研究的婦女中, 12 人 $(55 \%)$ 的胎兒纖連蛋 白測試結果呈陰性，沒有人在 7 天內分娩；6人使用 皮質類固醇及子宮收縮抑制劑，其中 1 人在 14 天內分 娩。餘下 10 人的胎兒纖連蛋白測試結果呈陽性。5人 在 7 天內分婏, 2 人在 14 天內分娩, 全部曾使用皮質類 固醇及子宮收縮抑制劑。胎兒纖連蛋白測試對於預測 7 天內分娩的敏感度和陰性預測值均為 $100 \%$ 。

結論 本研究顯示胎兒纖連蛋白測試在本地有高陰性預測 值, 可應用於有早產症狀的產婦。

Gestational age was calculated from the first day of the last normal menstrual period and confirmed by ultrasonographic measurements in the first or second trimester. For women in whom there was a discrepancy (the last menstrual period and ultrasound-based gestational age difference was $\geq 7$ days at $<14$ weeks, or $\geq 14$ days at $14-24$ weeks), gestational age was based on measurements obtained at the initial ultrasound examination.

During the gynaecological examination, a speculum using water as lubricant was introduced into the vagina before any digital or transvaginal ultrasound examination. Testing for rupture of membranes was performed by observing pooling of liquor in the posterior fornix, and asking the women to cough to observe any leakage through the cervical os. A polyester swab was inserted into the posterior fornix and rotated for 10 seconds to absorb cervicovaginal secretions. The swab was placed into the collection tube provided and the FFN test was analysed with TLiQ (FullTerm) [Hologic, Marlborough, US]. The result was either positive or negative, using $50 \mathrm{ng} / \mathrm{mL}$ as the cut-off. The test result was concealed from the women and the attending physician. Management was at the discretion of the attending physician. Quantitative data were expressed as means and standard deviations. Data were analysed using Student's $t$ test for continuous variables which were normally distributed and the Mann-Whitney $U$ test for skewed data. The Chi squared or Fisher's 
exact tests were used for dichotomous outcomes. A P value of $<0.05$ was considered statistically significant.

\section{Results}

In all, 25 women were considered suitable during the study period, but two refused and one was excluded because of a fetal congenital cardiac abnormality, leaving 22 women who were suitable and agreed to participate. The maternal demographic characteristics of these patients are shown in Table 1; 20 were singleton and 2 were twin pregnancies.

There were significantly more women with a positive FFN test who presented with vaginal bleeding $(\mathrm{P}=0.001)$. Overall, nine $(41 \%)$ presented with vaginal bleeding, of which seven also had abdominal pain. Of eight women who had vaginal bleeding and a positive FFN test, one had placental abruption and delivered vaginally within 24 hours of FFN test, and one had a show and delivered within 24 hours. Three others had an antepartum haemorrhage of

TABLE I. Maternal demographic characteristics

\begin{tabular}{|c|c|c|c|}
\hline \multirow[t]{2}{*}{ Characteristic } & \multicolumn{2}{|c|}{ Mean \pm standard deviation or No. } & \multirow[t]{2}{*}{$P$ value } \\
\hline & $\begin{array}{l}\text { FFN* positive } \\
\quad(n=10)\end{array}$ & $\begin{array}{l}\text { FFN negative } \\
\qquad(n=12)\end{array}$ & \\
\hline Age (years) & $33.3 \pm 3.1$ & $31.5 \pm 3.4$ & 0.259 \\
\hline Nulliparous & 6 & 10 & 0.221 \\
\hline History of preterm labour & 2 & 0 & 0.104 \\
\hline $\begin{array}{l}\text { Gestational age at recruitment } \\
\text { (weeks) }\end{array}$ & $30.5 \pm 3.2$ & $29.1 \pm 3.3$ & 0.210 \\
\hline \multicolumn{4}{|l|}{ Symptoms } \\
\hline Vaginal bleeding & 8 & 1 & 0.001 \\
\hline Abdominal pain & 8 & 12 & 0.104 \\
\hline
\end{tabular}

* FFN denotes fetal fibronectin

TABLE 2. Fetal fibronectin (FFN) test results and delivery outcomes

\begin{tabular}{|c|c|c|c|}
\hline \multirow[t]{2}{*}{ Delivery outcome } & \multicolumn{2}{|c|}{ Mean \pm standard deviation or No. } & \multirow[t]{2}{*}{$P$ value } \\
\hline & $\begin{array}{l}\text { FFN positive } \\
(n=10)\end{array}$ & $\begin{array}{l}\text { FFN negative } \\
\qquad(n=12)\end{array}$ & \\
\hline Gestational age at delivery (weeks) & $34.1 \pm 3.5$ & $38.5 \pm 2.0$ & 0.008 \\
\hline Mode of delivery* & & & 0.452 \\
\hline Vaginal & $6(4)$ & $9(2)$ & \\
\hline Caesarean section & $4(3)$ & $3(0)$ & \\
\hline \multicolumn{4}{|l|}{ Delivery } \\
\hline$<24$ Hours & 4 & 0 & 0.015 \\
\hline$<48$ Hours & 4 & 0 & 0.015 \\
\hline$<7$ Days & 5 & 0 & 0.005 \\
\hline$<14$ Days & 7 & 1 & 0.003 \\
\hline$<34$ Weeks & 5 & 1 & 0.029 \\
\hline$<37$ Weeks & 7 & 2 & 0.011 \\
\hline Use of tocolysis & 7 & 6 & 0.342 \\
\hline Use of corticosteroids & 7 & 6 & 0.342 \\
\hline Duration of hospital stay (days) & $3.8 \pm 1.8$ & $3.7 \pm 1.7$ & 0.812 \\
\hline
\end{tabular}

* The No. of cases delivering before 37 weeks are shown in brackets unknown origin and delivered within 7 days, 14 days, and at term. Another three had caesarean deliveries (one at 31 weeks for breech presentation following a preterm labour with the cervix dilated to $5 \mathrm{~cm}$ within 24 hours; one within 24 hours at 31 weeks for placental abruption and a twin pregnancy; one at 34 weeks for preterm prelabour rupture of membranes and a twin pregnancy 10 days after FFN test). The remaining woman who had vaginal bleeding and a negative FFN test had an antepartum haemorrhage of unknown origin and delivered at term.

The FFN test results and the delivery outcomes are listed in Table 2. A total of 12 (55\%) of the women had negative FFN tests; none delivered within 7 days, six of whom received corticosteroid and tocolysis, of which one delivered within 14 days. Regarding the 10 women ( $45 \%$ of those tested) who had positive FFN tests, five delivered within 7 days and two more within the next 7 days; all of them had received corticosteroids and tocolysis; the remaining three women received conservative management and delivered at term. Having a positive FFN was associated with delivery within 24 hours, 48 hours, 7 days, 14 days, before 34 weeks, and 37 weeks $(\mathrm{P}<0.05)$. The test's sensitivity and NPV were $100 \%$ to predict delivery within 7 days (Table 3). The sensitivity and NPV remained $100 \%$ to predict delivery within 7 days even if two cases with twin pregnancies were excluded. Both women with twin pregnancies presented with abdominal tightening and vaginal bleeding. They had a positive FFN test and were delivered for an obstetric indication. One delivered at 31 weeks and 3 days for placental abruption within 24 hours of the FFN test. The other delivered at 34 weeks and 3 days for preterm prelabour rupture of membranes 10 days after the FFN test.

\section{Discussion}

In previous studies, the NPV of the FFN test for delivery within 7 days was 99 to $99.5 \% .{ }^{8,9}$ Our results confirmed the high NPV of the test to predict preterm delivery. Honest et $\mathrm{al}^{7}$ reviewed 40 studies on the accuracy of the FFN test in symptomatic women. The likelihood ratio for a positive test was 5.4 (95\% confidence interval [CI], 4.4-6.7) for birth within 7 to 10 days, with a corresponding likelihood ratio for a negative test of $0.25(95 \% \mathrm{Cl}, 0.20-0.31) .{ }^{7}$ In the current study, the likelihood ratio for a positive and negative FFN test for delivery within 7 days were $3.4(95 \% \mathrm{Cl}$, 1.6-7.1) and 0.0, respectively.

In our study, significantly more women presenting with vaginal bleeding had positive rather than negative FFN tests (8 vs $1, \mathrm{P}=0.001$ ); five $(63 \%)$ of those with positive tests delivered within 7 days. Although vaginal bleeding may be related with preterm delivery, the presence of blood in the vagina may be associated with a false-positive FFN test. ${ }^{12}$ 
TABLE 3. The accuracy of fetal fibronectin tests*

\begin{tabular}{|c|c|c|c|c|c|c|}
\hline & $<24$ Hours & $<48$ Hours & <7 Days & <14 Days & $<34$ Weeks & $<37$ Weeks \\
\hline Sensitivi & $100(45.4-100)$ & $100(45.4-100)$ & $100(47.8-100)$ & 87.5 (47.3-99.6) & $83.3(35.8-99.5)$ & 77.8 (39.9-97.1) \\
\hline Specificity (\%) & $66.6(40.9-86.6)$ & $66.6(40.9-86.6)$ & $70.1(44.0-89.6)$ & $78.6(49.2-95.3)$ & $68.8(41.3-88.9)$ & $76.9(46.1-94.9)$ \\
\hline $\mathrm{PPV}^{\dagger}(\%)$ & $40(12.1-73.7)$ & $40(12.1-73.7)$ & 50 (18.7-81.2) & 70 (34.7-93.3) & 50 (18.7-81.2) & 70 (34.7-93.3 \\
\hline $\mathrm{NPV}^{\ddagger}(\%)$ & $100(73.5-100)$ & $100(73.5-100)$ & $100(73.5-100)$ & $91.7(61.5-99.7)$ & $91.7(61.5-99.7)$ & 83.3 (51.5-97 \\
\hline
\end{tabular}

* $95 \%$ Confidence intervals are shown in brackets

PPV denotes positive predictive value

NPV denotes negative predictive value

The clinical utility of the FFN test relates to its high NPV to identify women who were at low risk of preterm delivery. It may avoid unnecessary hospital admissions, prolonged hospital stays, transferal to tertiary units with advanced neonatal support, and the administration of tocolysis and corticosteroids. Based on the high NPV for delivery within 7 days, in our study tocolysis and corticosteroids could be withheld in women with a negative FFN test and reassessment considered after 7 days. Women with a positive FFN should be considered for receipt of corticosteroids and tocolysis. Dutta and Norman ${ }^{13}$ reviewed the efficacy of the FFN test in hospital admissions, from the perspective of length of hospital stay and cost savings. They detailed seven studies demonstrating a correlation of FFN test results with an actual estimate of health care cost savings, especially in women with a negative FFN test. ${ }^{13}$ Although observational studies suggested that the FFN test may be useful, no randomised study evaluating its use has demonstrated a clear benefit. ${ }^{14-17}$

Grobman et $\mathrm{al}^{14}$ randomised 100 symptomatic women to having an available FFN result and another group without such information. There was no difference in the number of hospital admission, use of tocolysis and corticosteroids, patient perceptions or total medical and non-medical costs. ${ }^{14}$ Lowe et $\mathrm{al}^{15}$ and Plaut et $\mathrm{al}^{16}$ randomised 97 and 100 patients respectively using a similar methodology, to evaluate whether an available FFN result would affect management, and found no difference in the use of betamethasone, tocolysis, and antibiotics, but did find fewer admissions in women with a negative rather than positive FFN test result. Lowe et $\mathrm{al}^{15}$ also encountered shorter hospital stays, but no such difference was found by Plaut et al. ${ }^{16}$ Ness et $\mathrm{al}^{17}$ randomised 100 women; one group had the transvaginal cervical length (TVCL) and results of any FFN test made available to them, and another group was not given such information. Those with TVCLs of $<20 \mathrm{~mm}$ underwent further treatment at the physician's discretion while those with TVCLs of $>30 \mathrm{~mm}$ could be discharged. The FFN test was performed in women with TVCLs of 20 to $29 \mathrm{~mm}$. The availability of such a result was not associated with a shorter interval between evaluation and discharge. However, having such information was associated with an increased admission rate. Vis et $\mathrm{al}^{18}$ reviewed the four above-mentioned randomised controlled trials and found that the absence of a beneficial clinical effect was largely related to the methodology. No fixed management protocol was used and the management of threatened preterm labour was left to the discretion of the treating physician, irrespective of the FFN result. Physician could still treat the women as 'high-risk' despite a negative FFN test. Accordingly, a randomised controlled trial using a fixed protocol with negative FFN test results is needed to evaluate the true clinical benefit and cost-effectiveness of the test.

The FFN test is easy to perform, whereas a transvaginal ultrasound scan for cervical length is technically demanding, operator-dependent, and can be time-consuming. Thus, the FFN test could be helpful in women with undetermined TVCLs. Hincz et $\mathrm{al}^{19}$ suggested using the test in women with TVCLs of 21 to $31 \mathrm{~mm}$. With this sequential combined approach, the sensitivity and NPV to predict delivery within 28 days increased to $86 \%$ and $97 \%$, respectively. ${ }^{19} \mathrm{Gomez}$ et $\mathrm{al}^{20}$ also suggested adding the FFN test to improve the prediction of preterm delivery when the TVCL is $<30 \mathrm{~mm}$. The FFN test is currently underutilised in public and private hospitals in Hong Kong. Obstetricians may prefer resorting to the TVCL, which provides another effective means of evaluating women with symptoms of preterm labour. Although TVCL requires expertise, there is an accreditation programme offered by the Fetal Medicine Foundation in the United Kingdom, which can be easily accessed through the internet (http://www.fetalmedicine. com/fmf/online-education/05-cervical-assessment/). Currently, ultrasonography is easily available for obstetricians, and TVCL can be readily available after the examination, with no additional cost. Shortening of the cervix is a strong predictor of preterm labour. Serial TVCL measurements could allow comparison with previous measurements; any change could provide obstetricians and women more information, and facilitate counselling and subsequent management. On the other hand, the FFN bedside kit is not widely available in Hong Kong; obstetricians need to wait around 30 minutes for a result, and each test entails an extra cost. Its NPV is useful when it comes to facilitating further obstetric management, 
but a positive result may not help. A false-positive FFN test can be due to prior sexual intercourse or cervical examination within 24 hours, which hinders its use in these situations. The limited PPV of the test may also lead to unnecessary treatment and maternal anxiety in low-risk patients. Another reason for underutilisation of the FFN test could be lack of familiarity, and worry about false-negative results leading to a preterm birth without corticosteroid protection. The legal liability environment may also influence the behaviour of obstetricians, leading to over-treatment rather than relying on the FFN result. Our study showed the NPV for delivery within 24 hours, 48 hours, and 7 days were $100 \%$, which should offer confidence to the local doctors and support its use to manage women who present with threatened preterm labour.

The main limitation of this study was the small sample size. Nevertheless, our results showing a high NPV were consistent with reports in the published literature..$^{8,9}$ The importance of this study is that it can increase awareness of the FFN test in Hong Kong and offer confidence to apply the test in clinical settings. Adherence to an agreed local protocol especially with a negative FFN result is critical. A second limitation was the inclusion of women with vaginal bleeding but without abdominal pain. Although uterine contractions were detected on tocodynamometry, this may represent Braxton Hicks contractions, rather than genuine preterm labour. Nevertheless, a negative FFN test may still be useful by offering attending physicians confidence to adopt conservative management. As management with FFN testing may not be beneficial without a fixed protocol, further randomised controlled trials addressing this issue may achieve better evaluation of the test's clinical benefit.

\section{Acknowledgement}

We thank Ms Joyce Yuen for the statistical analysis.

\section{Conflict of interest}

The TLiQ (FullTerm) and the testing kits during the study was sponsored by Hologic company.

\section{References}

1. Tucker J, McGuire W. Epidemiology of preterm birth. BM) 2004;329:675-8. cross ref

2. Goldenberg RL, Culhane JF, lams JD, Romero R. Epidemiology and causes of preterm birth. Lancet 2008;371:75-84. cross ref

3. Iams JD. Prediction and early detection of preterm labor. Obstet Gynecol 2003;101:402-12. cross ref

4. Herbst A, Nilsson C. Diagnosis of early preterm labour. BJOG 2006;113(Suppl 3):S60-7. cross ref

5. Murphy KE, Willan AR, Hannah ME, et al. Effect of antenatal corticosteroids on fetal growth and gestational age at birth. Obstet Gynecol 2012;119:917-23. cross ref

6. de Heus R, Mol BW, Erwich JJ, et al. Adverse drug reactions to tocolytic treatment for preterm labour: prospective cohort study. BMJ 2009;338:b744. cross ref

7. Honest H, Bachmann LM, Gupta JK, Kleijnen J, Khan KS. Accuracy of cervicovaginal fetal fibronectin test in predicting risk of spontaneous preterm birth: systematic review. BMJ 2002;325:301. cross ref

8. lams JD, Casal D, McGregor JA, et al. Fetal fibronectin improves the accuracy of diagnosis of preterm labor. Am J Obstet Gynecol 1995;173:141-5. cross ref

9. Peaceman AM, Andrews WW, Thorp JM, et al. Fetal fibronectin as a predictor of preterm birth in patients with symptoms: a multicenter trial. Am J Obstet Gynecol 1997;177:13-8. cross ref

10. ACOG practice bulletin no. 127: management of preterm labor. Obstet Gynecol 2012;119:1308-17. cross ref

11. Use of cervical fetal fibronectin and phosphorylated insulinlike growth factor binding protein 1 as screening tests for preterm birth. The Royal Australian and New Zealand College of Obstetricians and Gynaecologists. College Statement: C-Obs 26. 2011.

12. Feinberg RF, Kliman HJ. Fetal fibronectin and preterm labor. N Engl J Med 1992;326:708. cross ref
13. Dutta D, Norman JE. The efficacy of fetal fibronectin testing in minimising hospital admissions, length of hospital stay and cost savings in women presenting with symptoms of pre-term labour. J Obstet Gynaecol 2010;30:768-73. cross ref

14. Grobman WA, Welshman EE, Calhoun EA. Does fetal fibronectin use in the diagnosis of preterm labor affect physician behavior and health care costs? A randomized trial. Am J Obstet Gynecol 2004;191:235-40. cross ref

15. Lowe MP, Zimmerman B, Hansen W. Prospective randomized controlled trial of fetal fibronectin on preterm labor management in a tertiary care center. Am J Obstet Gynecol 2004;190:358-62. cross ref

16. Plaut MM, Smith W, Kennedy K. Fetal fibronectin: the impact of a rapid test on the treatment of women with preterm labor symptoms. Am J Obstet Gynecol 2003;188:1588-93; discussion 1593-5. cross ref

17. Ness A, Visintine J, Ricci E, Berghella V. Does knowledge of cervical length and fetal fibronectin affect management of women with threatened preterm labor? A randomized trial. Am J Obstet Gynecol 2007;197:426.e1-7.

18. Vis JY, Wilms FF, Oudijk MA, et al. Why were the results of randomized trials on the clinical utility of fetal fibronectin negative? A systematic review of their study designs. Am J Perinatol 2011;28:145-50. cross ref

19. Hincz P, Wilczynski J, Kozarzewski M, Szaflik K. Two-step test: the combined use of fetal fibronectin and sonographic examination of the uterine cervix for prediction of preterm delivery in symptomatic patients. Acta Obstet Gynecol Scand 2002;81:58-63. cross ref

20. Gomez R, Romero R, Medina L, et al. Cervicovaginal fibronectin improves the prediction of preterm delivery based on sonographic cervical length in patients with preterm uterine contractions and intact membranes. Am J Obstet Gynecol 2005;192:350-9. cross ref 